\title{
El rol de los saberes previos, la mediación y el intercambio en la lectura de un álbum
}

Martina Fittipaldi, Universitat Autònoma de Barcelona

Introducción

\author{
La ilustración es un arte instructivo: \\ amplía y enriquece nuestro conocimiento visual \\ y la percepción de las cosas. \\ Marion Durand
}

Varios estudiosos (Gombrich 1979; Parsons 2002; Duran 2007) han intentado analizar los modos en que los espectadores comprenden las producciones artísticas. Esto los ha llevado a reflexionar sobre la compleja naturaleza de la percepción humana como un proceso de selección y reorganización de datos, es decir, como un trabajo interpretativo. En esta línea, Arizpe y Styles (2004) se propusieron estudiar las respuestas dadas por niños de entre cuatro y once años de edad ante álbumes que empleaban dos códigos: el escrito y la imagen, y descubrieron así las enormes capacidades de los niños como lectores de textos visuales y las variadas relaciones que establecen entre el texto escrito y las ilustraciones.

¿Pero cómo leen los niños un álbum sin palabras? Este interrogante nos llevó a investigar sobre las respuestas dadas por los lectores ante la observación y análisis de un libro compuesto únicamente por imágenes: Emigrantes de Shaun Tan. Sin utilizar palabras, con una estructura que alterna pequeñas viñetas y grandes ilustraciones y con un estilo que pasa a menudo del hiperrealismo a lo fantástico, este libro narra el viaje del protagonista que deja su familia y su tierra, acosada por monstruos o fantasmas (vaya a saber si de la peste, del hambre o de la guerra...), y arriba a un nuevo lugar, cuya cultura le es totalmente desconocida. No obstante, allí conoce personas que le ayudan a integrarse y, con el paso del tiempo, logra establecerse y llevar a su familia.

Para responder a nuestra pregunta de investigación, realizamos primero una observación de clase y un cuestionario que nos sirvió para seleccionar a los informantes: doce niños de once y doce años pertenecientes a una escuela pública de Sant Joan Despí, con quienes llevamos a cabo dos talleres: uno integrado por seis niños catalanes 
y otro conformado por seis niños inmigrantes de primera generación y de diversa procedencia ${ }^{1}$. Con ambos grupos realizamos actividades que nos sirvieron como instrumentos de recogida de datos: sesiones de lectura y discusión del álbum, entrevistas semiestructuradas en parejas, una tarea en la que los niños debían seleccionar la ilustración que considerasen su favorita y, por último, la producción individual de un cómic sobre una historia de migración.

A lo largo del proceso, los lectores fueron reflexionando sobre diversos aspectos del libro y, especialmente, sobre las ilustraciones que lo constituyen. Algunos de estos aspectos son los que analizaremos a continuación.

\section{Aspectos del álbum relevados por los lectores}

Emigrantes es un libro que sorprende. Los niños lo dicen; en múltiples ocasiones manifiestan que este álbum es "curioso", "un poco raro", en definitiva, "un libro diferente”. ¿Por qué lo consideran distinto?, ¿en qué radica esta diferencia? Quizá el asombro de los estudiantes puede deberse al hecho de que prácticamente no tienen experiencia en la lectura de álbumes, ya que en el análisis de los cuestionarios encontramos que sólo dos de los doce alumnos hacen referencia a álbumes.

Sin embargo, sí están habituados a la lectura de las imágenes propias de los cómics o de los dibujos animados: siete de los doce se declaran lectores de este tipo de $\operatorname{textos}^{2} \mathrm{y}$, entre sus preferidos, nombran series televisivas (Los Simpson), historietas llevadas al cine o a la televisión (Mortadelo y Filemón, Las aventuras de Tintín) y mangas adaptados a series de dibujos animados conocidas como anime (Dragon Ball Z, Shin Chan, Love Hina, Doraemon... ${ }^{3}$ ).

Pero, a diferencia de lo que sucede con Emigrantes, las imágenes a las que están acostumbrados los niños siempre van acompañadas de lenguaje verbal. Una razón para el asombro es, entonces, la inexistencia de palabras:

Paola: [...] cuando me dijiste quieres hablar de emigrantes yo pensaba que yo iba a leer un libro y tenía otra imagen de eso $\downarrow$

Mediadora: y qué pensabas qué era $\uparrow$

Paola: no sé - un cuento - y que lo ibas a leer tú $\downarrow$ - pensaba yo porq- tiene tantas páginas \{(@) yera de imágenes\} 
Esta cita permite observar las representaciones que los chicos construyen sobre la lectura. Las ideas previas de Paola, en este caso, la llevaban a pensar la escena de lectura como la oralización de un texto narrativo por parte de la mediadora y, en sus palabras, podemos leer la frustración de esas expectativas (Eco 1979) y el asombro que le causa encontrarse con una clase distinta de texto, un texto largo pero sin palabras y pleno de ilustraciones.

Otro motivo de sorpresa es el tema abordado: la inmigración, pues según los niños esta temática no es para lectores pequeños, sino "para gente más madura". El hecho de que el libro esté construido sólo a partir de ilustraciones y encare un tema tan complejo como el de la inmigración les provoca una ruptura de esquemas, pues en sus reflexiones sobre el lector implícito (Chambers 1990) o lector modelo (Eco 1996), parece subyacer la creencia de que los álbumes tienen como destinatario sólo a niños muy pequeños ${ }^{4}$. Pero esta creencia se pone en duda al contemplar Emigrantes, que no es - ni parece - un libro para pequeños.

De cara a la formación lectora de los estudiantes, consideramos valiosa la capacidad del texto en sí y de la experiencia realizada para cuestionar los esquemas y creencias de los lectores, en la medida en que les permite redefinir y complejizar sus ideas sobre la función y destinatarios de los álbumes y sobre el proceso de comprensión de este tipo de textos.

No obstante, la complejidad de Emigrantes no está dada únicamente por el tema abordado, sino también por su aspecto formal, las ilustraciones que presenta, el modo en que se va construyendo la historia (o las historias) o los elementos de los que se echa mano para hacerlo, entre otros aspectos que los niños reconocen y analizan. A continuación revisaremos algunos de estos aspectos e indagaremos en las maneras en que los niños responden a ellos.

\section{El uso del color y la luz}

Como lo han demostrado investigaciones previas (Arizpe y Styles 2004; Kiefer 2005; Siro 2005), de todos los recursos utilizados para la elaboración del libro, a los niños les llama particularmente la atención el color. En nuestra investigación, le asignan a éste diversas funciones. 


\section{a. El color como modo de expresar el paso del tiempo}

A los niños les sorprende la paleta cromática usada en Emigrantes, pues "no salen colores, todo es blanco y negro", "a veces en sepia" 5 . Consideran que los colores son "raros", "antiguos", y sirven para indicar que el libro remite al pasado, aunque en realidad sea nuevo. O como afirma Emma: "nos quieren inducir a verlo como si fuera viejo pero a ver, sabemos que es nuevo".

Los estudiantes relacionan los colores escogidos para las ilustraciones con épocas remotas, y son conscientes de la intencionalidad del artista, de su búsqueda estilística: el autor "quiere que el libro parezca viejo" y por ello elige tonos amarillentos y colores sepia. O como sostiene Xavier: "sabe cómo hacerlo, que no lo pone así porque sí”.

Paola también es consciente de las intenciones del ilustrador cuando muestra cómo éste utiliza la luz para enfatizar la situación de explotación sufrida por los personajes: “mira, aquí el dibujante lo iluminó más para que se vieran todas las chicas aquí limpiando". Como afirma Gisela, este uso de la luz permite en otras ocasiones "diferenciar las cosas y ver entre la sombra y qué no es sombra [...] para ver si es que es día o noche". Alan, cuando observa la ilustración de los gigantes aspirando a los hombres (Figura 1), diferencia entre el uso del color y de la luz, pues indica que allí "no parece que fuera sólo en blanco y negro, puede ser que está... cómo está iluminado”. El manejo que este ilustrador hace de la luz y el modo "como utiliza los colores" lo llevan a pensar que se trata de un "profesional": “creo que es muy difícil hacer esto... bueno, para profesionales no debe ser tan difícil”.

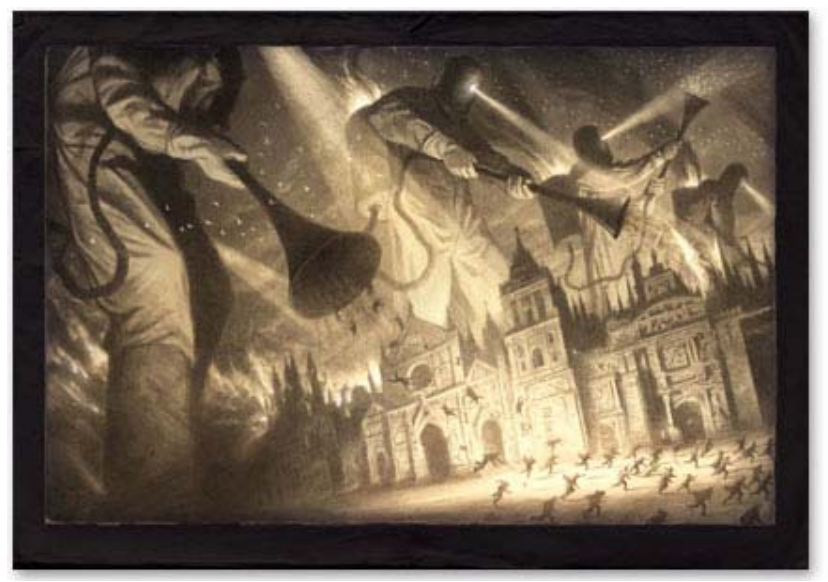

Figura 1. Alan observa la ilustración 
Carolina, por su parte, también reflexiona sobre los modos de utilizar la luz para crear atmósferas o para indicar determinadas horas del día. Observamos esto en el cómic que elabora para narrar una historia de emigración, pues allí la luz ingresa a las escenas paulatinamente, mediante un sol que se va llenando de color a medida que mejoran las posibilidades del protagonista, y que se transforma en una esfera amarilla y radiante cuando al final del relato el personaje se instala con su familia en el nuevo lugar.

\section{El color como modo de expresar los sentimientos}

Otras veces los niños vinculan los colores oscuros no sólo con la idea de lo antiguo, sino con la expresión de sentimientos o estados de ánimo. Cristina, por ejemplo, afirma que el color "es de la tristeza porque son inmigrantes", y Emma señala que el ilustrador "cuando hay momentos así tristes [...] utiliza tonos más apagados, y cuando son momentos felices, [...] tonos más alegres". Ambas citas muestran cómo los niños establecen un tipo de relación entre los colores y los sentimientos representados en la ilustración, que no analiza los matices, sino que se comprende de un modo general:

[...] los colores brillantes son alegres, los oscuros, tristes. No se atiende con detenimiento a los colores concretos, ni se les individualiza por sus respectivos caracteres; al contrario, más que analizarlos, se los reconoce [...] como si la conexión de los colores con los sentimientos fuera una conexión normal y bien establecida [...] Los colores se consideran por sí mismos, como poseedores de un carácter exclusivo independiente del contexto (Parsons 2002: 101-102).

Esto queda claro, por ejemplo, cuando Carles manifiesta que "el negro siempre es el color del mal", cuando Hilda señala que se utiliza este color para mostrar "algo malo" o cuando Carolina sostiene que el color se usa de forma "más o menos igual en todos" los dibujos.

Sin embargo, y aunque bajo el mismo patrón o esquema (oscuro/malo; claro/bueno), en otras ocasiones los niños analizan los colores y descubren diferencias o matices entre ellos, como cuando Cristina plantea que, aunque algunas ilustraciones del libro expresan alegría, ésta no se muestra como comúnmente a través de "un color amarillo o verde fuerte sino que: [...] como va de negro, usa un color clarito". Esta intervención conduce a Gisela a comprender las ilustraciones como un modo de expresar la subjetividad, tanto por parte del artista como por parte del espectador pues afirma: "a través de una pintura uno expresa [y] siente a lo mejor lo que está expresando una pintura". 


\section{El color como modo de advertir al lector}

Durante la entrevista, Carles también va más allá del negro y blanco señalados en un principio, comienza a reconocer otros colores y posibles combinaciones entre ellos. Pero no observa sólo los dibujos sino también los marcos, donde además del recurso cromático cobra importancia también el diseño, pues los malos momentos no se indican sólo mediante colores oscuros, sino mediante páginas que parecen "roñosas, rotas, arrugadas".

Carles da al color de los marcos la función de advertir al lector sobre lo que encontrará en el texto, pues plantea que los bordes grises o negros "a lo mejor te están explicando de alguna manera para que la gente [a la] que no le gusta el sufrimiento [...]

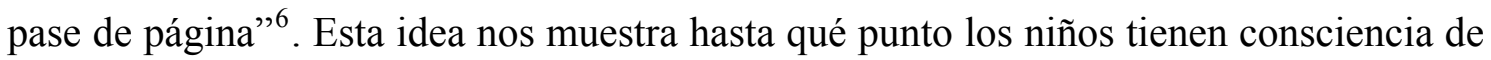
la intencionalidad del artista y de la figura del destinatario.

\section{El color como modo de diferenciar historias}

Pero los diferentes marcos y sus colores no sirven únicamente para "advertir" al lector sino también para distinguir las diversas historias insertas en el relato. Los niños reconocen este recurso, pues a la pregunta de la mediadora: “¿y cómo sabemos que ésta es otra [...] historia?" responden que "está diferente recuadrado" pues "aquí lo empiezan a recuadrar como si ya fuese un recuerdo o algo". No obstante, a veces este reconocimiento les demanda un proceso de análisis mayor: esto sucede por ejemplo cuando Paola, a partir de los interrogantes realizados por la mediadora, piensa y descubre que las historias de cada uno de los personajes que transitan por el libro está señalada en páginas que tienen diferentes colores y tipos de marco: “AH [...] MIRA COMO LE DA COLOR MÁS FUERTE POR EL BORDE, le da más colores, más le alumbra y más se hace reconocida la página". La expresión "AH" junto con el incremento de volumen (marcado por el uso de mayúsculas) permiten descubrir que las preguntas de la mediadora y el tiempo destinado a contemplar la ilustración posibilitan la reflexión y construcción de nuevos significados.

A lo largo de los casos citados, descubrimos que los niños aluden repetidamente al recurso cromático y le otorgan múltiples sentidos: sirve para señalar el tiempo, los sentimientos y estados de ánimo de los personajes, los momentos de mayor dolor o crudeza, o adquiere una función estructural en la narración al ayudar a los lectores a distinguir los relatos insertos en la historia principal ${ }^{7}$. 
Los lectores también tienen en cuenta el uso de la luz y observan cómo se utiliza este recurso para distinguir en las ilustraciones los lugares abiertos y cerrados, los diferentes momentos del día o los paisajes cercanos o lejanos. Los ejemplos analizados muestran que los estudiantes reflexionan sobre la luz y el color de las ilustraciones a partir de la construcción de hipótesis de carácter diversificado. Éstas últimas nos permiten advertir la consciencia que los niños poseen del medio, de las intencionalidades del artista, de la figura del destinatario y de la función que pueden cumplir algunos elementos en la construcción del relato.

A través de los ejemplos estudiados observamos también cómo los estudiantes, al pensar las preguntas realizadas por la mediadora o por sus compañeros, al escuchar las intervenciones de los otros o al efectuar comentarios, se implican en un proceso que los lleva a profundizar sus observaciones y a reorganizar sus esquemas cognitivos.

\section{El movimiento y la perspectiva}

El movimiento es otro aspecto destacado por los niños en Emigrantes. La estructura del cómic, el uso de viñetas constituye para ellos una forma de hacer "más fácil" la lectura, pues permite "hacernos una idea de lo que se trata", y observar con mayor rapidez no sólo "qué está haciendo" sino cómo "se va moviendo el personaje".

Pese a que las ilustraciones se diferencian del cine pues son imágenes estáticas (Bosch 2007), los niños acercan ambos campos del arte al afirmar que el libro de Shaun Tan "es como una película pero hecha en fotos". Esta frase de Calin sintetiza el carácter doble de Emigrantes, que combina la inmovilidad de las imágenes con el desplazamiento propio de una cámara cinematográfica. Podemos decir entonces que este libro está compuesto por ilustraciones similares a "fotos", pues son representaciones estáticas de estilo hiperrealista - aunque, según los niños, en algunos pasajes observamos también un estilo "surrealista" o "futurista"- pero, al mismo tiempo, la secuencialidad y el afán de movimiento que poseen algunas ilustraciones permiten compararlo con un film o con los dibujos animados.

Así, aunque saben que en el libro las imágenes están fijas, gracias a su minuciosa contemplación los niños descubren la existencia de ciertos modos de sugerir el movimiento. Uno de éstos es la repetición de escenas muy similares que "parecen 
iguales" pero no lo son, pues hay entre ellas pequeños cambios, "pequeños movimientos" que sirven para indicar el desplazamiento.

Otro modo de sugerir el movimiento es el uso de los colores, texturas y maneras de dibujar, que pueden ser más nítidas o más borrosas para indicar una marcha lenta o más rápida. En la historia del anciano que ha participado en una guerra y ha perdido allí la pierna hallamos una página construida mediante pequeñas viñetas, donde se enfocan sólo las piernas de los soldados que van recorriendo los distintos caminos (Figura 2).

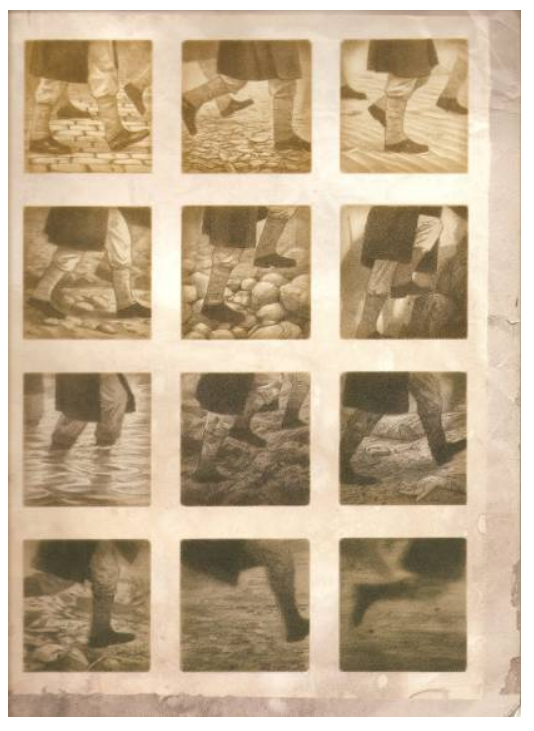

Figura 2. Las piernas de los soldados

En esta secuencia comprendemos los movimientos y cambios en las condiciones de vida que van sufriendo los soldados a partir de muchos guiños, como el tipo de imagen, que en las primeras viñetas es más nítida y poco a poco se va difuminando; o el uso de los colores y de la luz, que se apaga paulatinamente y provoca así que los paisajes vayan tornándose cada vez más sombríos.

A partir de la observación y de las preguntas formuladas por la mediadora, los niños reconocen el uso de algunos de estos recursos como el color, la textura o el grado de nitidez de las imágenes:

Mediadora: y cómo te das cuenta de que [el personaje] está corriendo $\uparrow$

Paola: porque está ese color como raya-o no $\uparrow$ sí rayado-

Mediadora: sí $\downarrow$ - como borroso no $\uparrow$ así com-

Paola: AHÍ -TÁ COMO BORROSO - se ve su reflejo - su reflejo está quieto y está borroso $\downarrow$

La cita muestra como Paola se apropia del término utilizado por la mediadora en busca de precisión lingüística, en un intento por encontrar la palabra justa. En otras situaciones 
hallamos esta misma búsqueda, señalada también por investigadoras como Arizpe y Styles (2004). Aunque resulte paradójico, tal vez la lectura de un libro sin palabras, como Emigrantes, podría colaborar en el aprendizaje lingüístico, pues llevaría a los niños a pensar sobre los vocablos, a querer ser precisos. Esta reflexión nos lleva a sostener con Bruner (1986) que "la única forma en que se puede aprender el uso del lenguaje es usándolo de manera significativa" (p. 118).

En cuanto a los aspectos destacados en la lectura de imágenes, muchos niños aluden a los recursos mencionados, pero algunos no sólo los indican sino que buscan darles sentido. Esto sucede cuando Carolina e Hilda observan la figura 2 y dialogan sobre las razones por las que el artista utiliza el claroscuro o va modificando el grado de nitidez de las imágenes. Para Carolina, la intención de esta manera de ilustrar y, en especial, del uso del esfumado es el deseo de evitar la exhibición de "la sangre", del sufrimiento, pensamiento cercano al de Carles, quien sostiene que el autor elige los tonos sepia porque no quiere que el dolor se vea "muy destacado". Hilda, en cambio, asocia los trazos difuminados con el "movimiento", pues el personaje "está corriendo", pero considera que los recursos utilizados colaboran para mostrar al lector un crescendo, pues “cada vez está más descontrolado todo".

La lectura compartida provoca en los niños una toma de conciencia sobre los modos de señalar el movimiento en la imagen. Esto se observa en algunas de sus producciones, pues mientras hay quienes apelan a convenciones gráficas ya conocidas para señalar el movimiento en la imagen (flechas o líneas cinéticas), otros como Emma, por ejemplo, intentan incorporar la velocidad o el movimiento remarcando la diferencia entre lo nítido y lo borroso para mostrar cómo se observan los objetos y los paisajes desde la ventanilla de un tren en marcha (Figura 3).

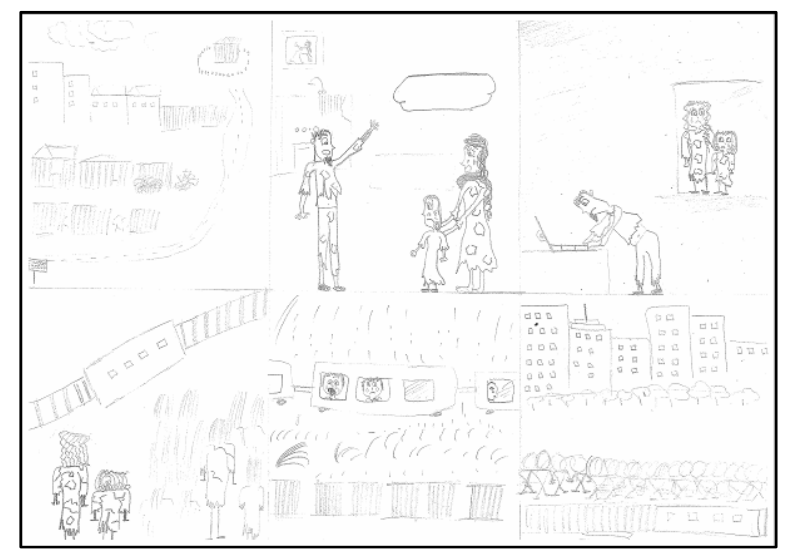

Figura 3. Vista de la ventanilla del tren 
La perspectiva es otro de los recursos que los niños reconocen al observar Emigrantes. Los alumnos catalanes lo señalan sin ambages $\mathrm{y}$, aunque los inmigrantes no utilizan metalenguaje para referirse a esto, en sus comentarios tienen en cuenta este aspecto. Paola, por ejemplo, alude a la diversidad de enfoques que caracteriza al libro a partir del señalamiento de los distintos tamaños que poseen los elementos en una viñeta con respecto a las siguientes: "mira aquí está grande, mediano, pequeño, se va alejando...". Pero no sólo indica las diferentes medidas de los objetos, sino el hecho de que las dimensiones cambian de acuerdo a la distancia establecida entre el punto de mira y el objeto observado. Adrián explica esto al manifestar que "cuando el tren se está yendo como que estás aquí, [...] se está alejando hasta que no se ve”. Gisela también alude a este recurso cuando observa el barco en las diferentes viñetas y plantea que "se ve cada vez más lejos".

Los alumnos inmigrantes reflexionan sobre las distancias o los enfoques, y algunos utilizan en sus cómics sobre historias de emigración este conocimiento. Naima, por ejemplo, ofrece la vista aérea de un tren surcando el camino, primero de cerca $y$ luego desde más lejos (Figura 4), y Gisela usa este recurso al elegir primeros planos y, a continuación, tomas de lejos.

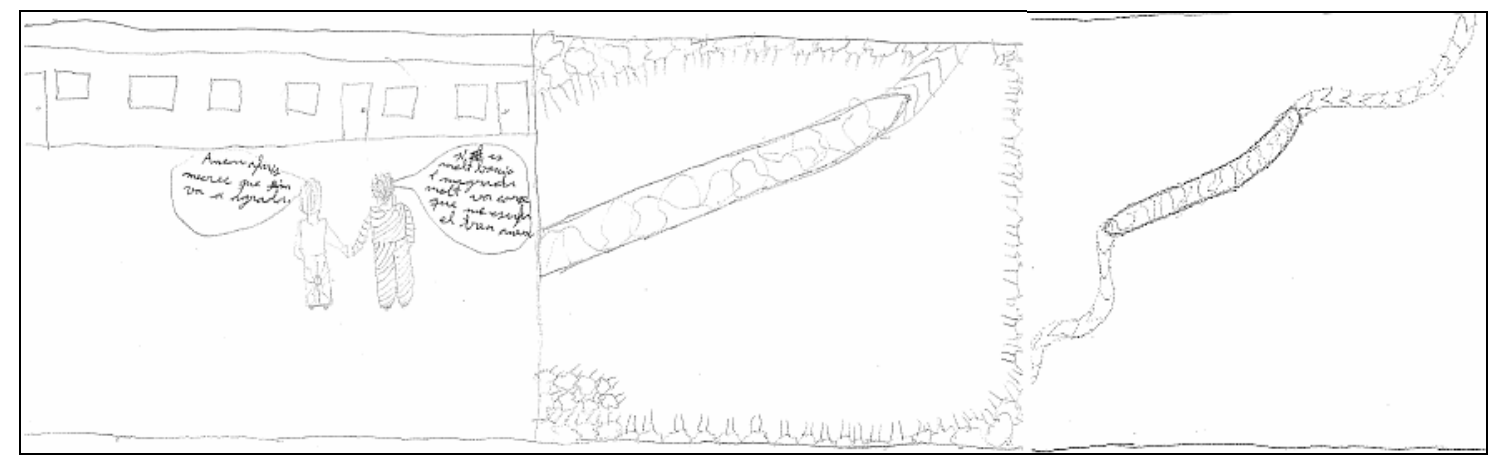

Figura 4. Vista aérea de un tren

Los niños catalanes también mencionan este recurso, a veces con palabras coloquiales y otras con términos como zoom, por ejemplo. Además, para explicar los cambios observados entre las viñetas, a menudo emplean vocablos como tomas o cámara lenta. Éstos remiten al discurso propio del cine o de la televisión y constituyen indicadores de la enorme influencia que ejercen los medios audiovisuales en la mirada y en las maneras de hablar utilizadas por los niños para referirse al texto. No obstante, las características particulares de un libro como Emigrantes, cuyas ilustraciones recuerdan al lenguaje 
cinematográfico, pueden también configurar el punto de partida para que los niños utilicen este vocabulario.

A diferencia de los niños recién llegados, quienes no aluden a la multiplicidad de puntos de vista presentes en el texto, pues no señalan, por ejemplo, la existencia de planos objetivos o subjetivos, los catalanes expresan una mayor conciencia de las diferentes perspectivas desde las que se construye el relato. Señalan así que los lectores observan "desde la visión de la niña cómo se aleja el tren", o recuerdan que "en el capítulo anterior [...] algunas de las viñetas tenían la perspectiva del hombre pero también estaba la de la hija". Este último comentario nos remite a la lectura compartida de la parte I de Emigrantes, a la construcción de sentido realizada durante esa sesión en torno a la hija del protagonista y a las diferentes miradas desde las que se construye el relato:

Mediadora: y por qué aquí en la última viñeta de esta página aparece [...] el rostro del padre cortado $\uparrow$

Carolina: pues porque: pues la niña va así con la maletilla y como que - o sea- lo mira:

Hilda: sí - lo mira así como desde abajo - como que ella es más bajita $\downarrow$

Mediadora: claro $\downarrow$ y por qué se verá así - desde abajo - [...]

Hilda: $=$ como desde la visión $=$ de ella $[. .$.

Mediadora: ah - bien - claro $\downarrow$ es como si se nos mostrara desde la perspectiva de la niña - no个

En esta cita, la pregunta de la mediadora suscita la construcción de hipótesis por parte de los estudiantes, quienes van explicitándolas y elaboran así un conocimiento relativo al uso de las perspectivas en la narrativa visual. En otro momento, mientras observan la ilustración en la que el protagonista y su familia arriban a la estación de tren, Carolina retoma este saber construido colectivamente y enfatiza en el punto de vista de la niña. Señala que ésta mira para arriba pues le llama la atención el tren. Esto provoca una discusión, en la que Emma interviene para replicar que "un tren no va para arriba, no vuela", pero sus compañeros le señalan que ésta no es la única posibilidad al explicitar sus inferencias, como por ejemplo que "la niña es bajilla" y por eso "desde su lugar no puede ver todo". La riqueza que supone el intercambio de ideas provoca que, durante la entrevista, Emma vuelva sobre el tema de las perspectivas para reflexionar acerca del carácter "polifónico" (Bajtin 1988) de Emigrantes. Sostiene así que el autor/ protagonista (pues parece confundir ambos conceptos) "lo ha querido plasmar en un libro en diferentes perspectivas para que nos demos cuenta lo que siente su hija, lo que siente la madre y lo que siente él y otros compañeros". 
La lectura compartida de Emigrantes y la reflexión sobre los diversos enfoques desde los que se construye la narrativa visual se transforma en conocimiento para los niños, pues sus dibujos, aunque en muchos casos son esquemáticos, incorporan el uso de distintos puntos de vista. En sus cómics observamos así miradas aéreas, personajes ubicados de espaldas al lector, o viñetas que parecen mostrar la mirada del protagonista, que se ofrece a enseñarnos el mundo desde su perspectiva.

Esta función del diálogo y de la reflexión como elementos que posibilitan la apropiación de saberes posteriormente utilizados en las producciones podría ejemplificarse con el caso de Hilda. Durante la primera sesión ella participa activamente y se detiene en una ilustración en la que, según afirma, “es como si [el protagonista] mirara en torno, y allí están las personas". Esta reflexión sobre el uso de la perspectiva en el libro leído parece reaparecer al realizar su propia historieta, pues allí Hilda utiliza una viñeta cortada de manera oblicua, que muestra, de un lado, el rostro de la protagonista que arriba a la nueva ciudad y mira a su alrededor, y del otro, lo que parece estar observando: la gente que sale como en bandada de la estación para buscar un lugar de cobijo (Figura 5).

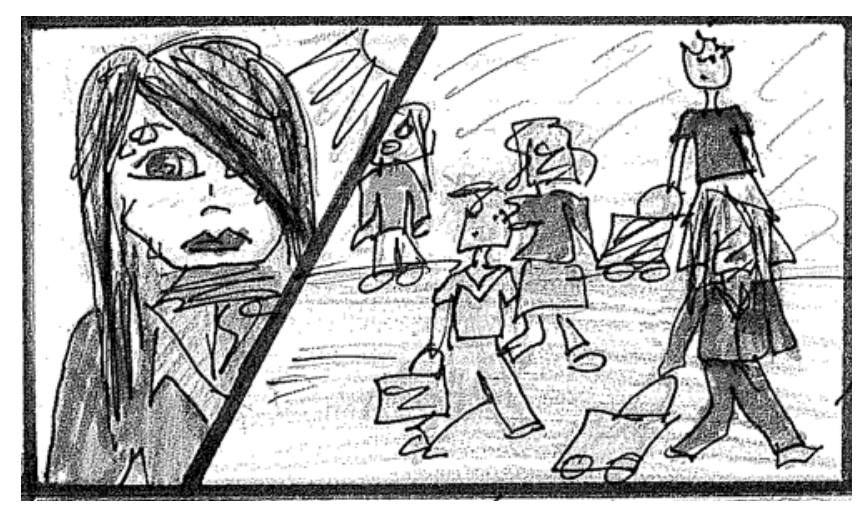

Figura 5. Buscando cobjio

Tal vez ejemplos como el anterior (y muchos de los analizados) ayuden a modificar la visión que a veces tenemos los docentes sobre la lectura compartida de textos artísticos, pues en ocasiones - y desde una mirada eferente (Rosenblatt 1978) - la entendemos como un espacio ambiguo en el que no tenemos muy claro qué estamos enseñando, o si estamos haciendo algo curricularmente útil, quizá porque no somos conscientes de la riqueza de este proceso y de los movimientos internos que se activan en cada uno de los que participan en el encuentro con los demás y con los textos (Devetach 2003). 


\section{La materialidad del libro y su proceso de construcción}

En Emigrantes los aspectos materiales son muy importantes y llevan a reflexionar sobre el libro como objeto. Pero no como un objeto cualquiera, sino como un pequeño cajón que encierra entre sus páginas la experiencia de los hombres que, en el camino, van construyendo sus vidas. En el libro de Shaun Tan esas vivencias no se cuentan con palabras, sino a partir de imágenes y de otros elementos que invitan a analizar su carácter material. Desde un primer momento, tanto los niños catalanes como los inmigrantes subrayan algunos de estos aspectos, propios de los álbumes posmodernos, que ayudan al ilustrador a elaborar un libro que es "como un álbum de fotos".

Los niños atienden a "la condición de los libros como artefactos materiales" (Arizpe 2007: 8) al señalar el uso de trozos de cuero o de tela, como el que aparece bajo "el código de barras", o al destacar "la foto manchada y con pegamento" presente en la portada y contraportada del libro, e infieren que se recurre a estos elementos para indicar al lector que se trata de un libro "antiguo". Sin embargo, plantean que en realidad el libro es nuevo, pues "las páginas están plastificadas - bueno las tapas" y difieren de las antiguas por "el material [de] que están hechas [...] no son de ese papel típico, como las de antes".

También les llaman la atención los "sellos", las ilustraciones que - como fotos simulan estar pegadas "con celo", las tarjetas de inspección y los carnés de identidad que aparecen en la portadilla y en la página de créditos. A éstas últimas, en especial, los niños buscan otorgarles un sentido relativo al tema del libro. Este intento de relacionar el aspecto material con la historia contada les lleva a pensar que la documentación incluida como fondo en algunas páginas podría pertenecer al protagonista y constituir así un testimonio de su recorrido, o - como afirma Adrián - podría haber sido tomada de otros álbumes familiares.

Alan queda cautivado por el uso de esta técnica, y considera que los documentos están puestos allí por algún motivo. Durante las entrevistas, por ejemplo, cuando dialogamos con los niños sobre el protagonista y su falta de identidad, la mayoría de ellos sostiene que esto se da por razones de coherencia, ya que "no puede salir el nombre del protagonista porque eh... no se puede escribir porque es un libro [...] ilustrado", por el deseo de mantener el anonimato, pues el narrador "no quiere que 
sepan su nombre, a lo mejor" o - como plantea Gisela - porque los símbolos utilizados en el libro son tan ininteligibles para nosotros que, aunque allí estuviera colocado el nombre del emigrante, no podríamos enterarnos.

En cambio, cuando conversamos con Alan sobre este tema, al principio él no ofrece motivos para explicar la falta de nombre del protagonista, pero a lo largo de la entrevista intenta buscar su denominación, hasta que manifiesta con asombro que la ha encontrado en la tarjeta de inspección que aparece en la portadilla: "ya sé cómo se llama: [...] be dam- berg". Este proceso de búsqueda activa y de construcción de hipótesis, no sólo a partir de las ilustraciones sino de los distintos materiales que constituyen el texto, lo lleva a considerar que el libro es "interesante", pues a cada momento "estamos haciendo algo para averiguar lo que pasó [y esto da] como un poco de intriga".

También hallamos este deseo de dar sentido cuando los niños observan las manchas, arrugas, rayas y demás recursos metaficcionales que aparecen en el libro y que, en un primer momento, los sorprenden mucho. Paola, por ejemplo, cuando mira el estado del ejemplar que tiene en sus manos, su apariencia antigua y ruinosa sólo atina a preguntar: “¿así te ha venido?”, e Hilda se admira al descubrir que las arrugas que creía "reales" están hechas intencionalmente y conforman también una parte del libro.

Al contemplar las manchas en las páginas, los niños construyen hipótesis diferentes: éstas podrían ser "como unas lágrimas" (Calin) que han caído sobre las fotos, indicios de que "ha caído agua" (Adrián), "sangre" o marcas "de lo antiguo" (Alan), señales del paso del tiempo, que les llevan a recordar "los libros de [la] abuela" (Hilda).

A otros niños, como a Carles, no les interesa tanto dar sentido a las manchas, sino pensar en los recursos utilizados por el ilustrador para conseguir el efecto de sombreado que, en su opinión, es “de ordenador". Durante la entrevista él nos cuenta que su hermano trabaja con diseño asistido por ordenador; tal vez esa sea una de las razones que lo impulsan a analizar detenidamente los recursos y materiales usados por Shaun Tan en el afán de explicar el proceso técnico de construcción del libro como objeto. Notamos esto, por ejemplo, cuando hace referencia a los cortes de página, al sombreado, al uso de la ilustración manual y de software de diseño.

Aunque no con tanta experticia, otros niños también aluden al proceso de producción del texto y plantean, como Naima, que para elaborarlo se copiaron y reunieron las ilustraciones, "haciendo [un] libro", o sostienen que hay páginas reducidas o que pertenecen en realidad a otros libros y han sido recortadas y colocadas aquí. 
La manera de ilustrar de Shaun Tan a los niños les recuerda al cómic "porque... algunos cómics se dibujan así, sólo... sólo a lápiz" y a programas televisivos como Art Attack, donde analizan los modos en que se construyen las ilustraciones. Este tipo de programas, y su propia experiencia como "niños de la era digital” (Marsh 2005), hace que tanto inmigrantes como catalanes sean capaces de comprender y explicitar muchas de las convenciones gráficas utilizadas en Emigrantes.

Sin embargo, no sólo hacen uso de convenciones propias de la narrativa visual, sino de saberes sobre los modos de organizar el espacio y de incorporar los datos en los libros "con palabras". Durante la primera sesión ambos grupos observan la primera portadilla, llena de extraños símbolos, e inmediatamente descubren que se encuentran frente a un lenguaje, inventado quizá, pero lenguaje al fin; "otro idioma” que, para Carles, se parece al "indio" o al "griego". Ante la pregunta de la mediadora sobre qué significan los símbolos, tanto catalanes como recién llegados leen y releen intentando descifrarlos. Reconocen entonces "que algunas letras están al revés", pero que indican el título y el autor del libro. Cuando la mediadora les pregunta cómo lo saben, Andreu manifiesta: “es lo más normal”. ¿Por qué les parece "lo más normal”? Quizás porque tienen experiencia en el manejo de libros: saben qué datos se colocan generalmente en la portadilla y cómo se organizan espacialmente. Vemos así como los estudiantes apelan a otra forma de lectura que tienen internalizada (Brice 2004), no tanto lingüística como espacial y cultural, pues gracias al tamaño de las letras, a su ubicación en la página y a otros indicios similares, pueden interpretar que en ese lenguaje extraño están cifrados el nombre del autor y el título del libro.

\section{Conclusión}

Si desandamos el camino realizado, descubrimos que los niños, al mirar detenidamente Emigrantes de Shaun Tan y al conversar sobre éste, señalan múltiples aspectos presentes en las ilustraciones, y parecen comprender sin demasiadas dificultades la compleja gramática utilizada en el libro (Arizpe et al. 2008), pues su familiaridad con los discursos mediáticos les otorga experiencia para entender, por ejemplo, el uso de la luz y del color, las expresiones de los personajes, los modos de sugerir movimiento y de mostrar las diversas perspectivas, o las maneras en que se construye el libro como objeto, entre otros muchos aspectos. 
No obstante, los ejemplos presentados a lo largo del artículo muestran que en la comprensión juegan un rol importantísimo no sólo los conocimientos previos de los lectores, sino también otros muchos factores que, como enseñantes, hemos de tener en cuenta en la formación lectora de nuestros alumnos.

Entre ellos podemos destacar el papel del mediador como puente entre el texto y los lectores, como guía que ayuda a los niños a acercarse al libro, a aguzar la mirada y a prestar atención a los diversos planos o elementos, a fin de otorgarles sentido.

Sin embargo, no sólo son importantes las formas de mediación sino también los contextos de intercambio, a partir de los cuales los niños pueden poner en relación lo que conocen con los textos que leen, además de escuchar los comentarios e intervenciones de sus compañeros. Esta conversación entre iguales durante la lectura posibilita que los niños expresen y compartan distintos conocimientos y perspectivas sobre lo leído, lo que les permitirá apropiarse y reformular esos saberes a fin de utilizarlos en otras circunstancias.

Pero para ello es necesario proporcionar a los estudiantes libros que, como Emigrantes, abran un espacio para el asombro, para la curiosidad, y permitan la reflexión y el intercambio, y es imprescindible también ofrecerles el tiempo y espacio adecuados para observar y analizar los textos, para expresar sus opiniones o pensamientos y confrontar saberes adquiridos en diversos ámbitos, a fin de construir, entre todos, una verdadera comunidad de lectores: una comunidad donde los conocimientos se critiquen, se pongan en cuestión para, así, lograr que adquieran un carácter más social, más profundo y más complejo.

\section{Referencias}

Arizpe, E. (2007) 'This book is about books': Literacy, culture and metaliterary awareness. En: Simposio Nuevos impulsos en la investigación sobre el álbum: aspectos estéticos y cognitivos del álbum. Barcelona: UAB.

Arizpe, E. y Styles, M. (2004) Lectura de imágenes. Los niños interpretan textos visuales. México: F.C.E. $1^{\circ}$ ed. 2003 Children Reading Pictures: Interpreting Visual Texts. London: Routledge Falmer.

Bosch, E. (2007) Hacia una definición de álbum. AILIJ, Anuario de Investigación en Literatura Infantil y Juvenil, 5, pp. 25-45.

Brice, S. (2004) El valor de la lectura de cuentos infantiles a la hora de dormir: habilidades narrativas en el hogar y en la escuela. En: Zavala,V.; Ñiño-Murcia, M. y Ames, P. (eds.), Escritura y sociedad. Nuevas perspectivas teóricas y 
etnográficas, Lima: Universidad del Pacífico. $1^{\circ}$ ed. 1998 Local Literacies. Reading and Writing in One Community. London: Routledge.

Bruner, J. (1986) El habla del niños. Barcelona: Paidós. $1^{\circ}$ ed. 1983: Child's Talk. Learning to use language. London: Norton.

Chambers, A. (1990) The Reader in the Book. In: Hunt, P. (ed.) Children's literature. The development of criticism. London: Routledge.

Colomer, T. y Manresa, M. (2008) Lecturas adolescentes: entre la libertad la prescripción. En: Camps, A. y Milian, M. (eds.), Miradas y voces. Investigación sobre la educación lingüística y literaria en entornos plurilingües, pp. 119-130. Barcelona: Graó.

Devetach, L. (2003) La construcción del camino lector. En: Cuadernos de Iberoamérica. Escuelas que hacen escuela II. Los caminos de la palabra. Bs. As.: OEI.

Duran, T. (2007) Àlbums i altres lectures. Anàlisi dels llibres per a infants. Barcelona: Associació de Mestres Rosa Sensat.

Durand, M. (1975) L’image dans le livre pour enfants. París: L'École des loisirs.

Eco, U. (1979) Lector in fabula. Barcelona: Lumen.

Eco, U. (1996) Seis paseos por los bosques narrativos. Barcelona: Lumen.

Gombrich, E. H. (1979) Arte e ilusión. Estudio sobre la psicología de la representación pictórica. Barcelona: Gustavo Pili.

Kiefer, B. (2005) Una mirada más allá de las preferencias del libro-álbum. Revista Parapara clave El libro-álbum. Invención y evolución de un género para niños, 1, pp. 196-203.

Manresa, M. (2005) Les obres literàries completes a secundària: del lector a la programació. Llicència d'estudis retribüida. Barcelona: Departament d'Educació.

Marsh, J. (Ed.) (2005) Popular Culture, New Media and Digital Literacy in Early

Childhood. Abingdon: Routledge Falmer.

Nodelman, P. (2005) Pistas y secretos: cómo funcionan los libros-álbum. Revista Parapara clave El libro-álbum. Invención y evolución de un género para niños, 1, pp. 134-149.

Parsons, M. J. (2002) Cómo entendemos el arte. Barcelona: Paidós. $1^{\circ}$ ed. 1987. How we understand art. Cambridge: The Press Syndicate of the University of Cambridge.

Rosenblatt, L. (1978) The Reader, the Text and the Poem. Illinois: Southern Illinois University Press.

Siro, A. (2005) El desafío de la continuidad: una mirada sobre la intervención del mediador en la formación de lectores de álbumes. México: CONACULTA.

Tan, S. (2007) Emigrantes. Cádiz: Bárbara Fiore. $1^{\circ}$ ed. 2006 The Arrival. Australia: Lothian Books.

Referencia de la autora:

Martina Fitipaldi es profesora en Letras por la Universidad Nacional de Salta (Argentina) y Máster en Didáctica de la Lengua y la Literatura por la Universidad Autónoma de Barcelona (España). Ha sido docente en los niveles de educación secundaria y universitaria. Como mediadora e investigadora del Plan Nacional de Lectura de Argentina, ha impartido cursos, talleres y seminarios. Como investigadora ha presentado comunicaciones y ha publicado artículos sobre diversos temas relacionados con la lectura y la literatura.

Actualmente, y gracias a una beca del Ministerio de Asuntos Exteriores y la Agencia Española de Cooperación Internacional (MAE-AECI), cursa el Doctorado en Didáctica de la Lengua y la Literatura 
de la Universidad Autónoma de Barcelona (UAB) y el Máster en Libros y Literatura para Niños y Jóvenes, organizado por el Banco del Libro de Venezuela y la Universidad Autónoma de Barcelona. martina.fittipaldi@uab.cat

${ }^{1}$ Aunque la mayoría de los inmigrantes eran de origen latinoamericano (Gisela y Adrián de Bolivia, Alan de Ecuador, y Cristina de Perú), había también un niño rumano, Calin, y una niña marroquí, Naima. A fin de proteger la identidad de los informadores, todos los nombres que utilizamos son seudónimos. Para los seis niños catalanes elegimos los nombres de Carles, Emma, Xavier, Hilda, Andreu y Carolina.

${ }^{2}$ Tanto entre los niños catalanes como inmigrantes, son los hombres quienes prefieren - por amplia mayoría - la lectura de cómics. Aunque por el estrecho alcance de nuestro trabajo no es posible generalización alguna, podría ser interesante indagar en esta línea en estudios posteriores.

${ }^{3}$ La investigación desarrollada por Mireia Manresa (2005) arroja información similar en cuanto a la preferencia de los adolescentes por el género manga y por títulos como los mencionados.

${ }^{4}$ Esta idea es señalada también por Colomer y Manresa (2008), quienes afirman que "a menudo se produce un rechazo temprano de los libros ilustrados o cortos, [pues] son vistos como libros adecuados para niños pequeños" (2008: 126).

${ }^{5}$ Aunque los niños tenían a su disposición variedad de lápices, marcadores y rotuladores para elaborar sus cómics, la mayoría de ellos apenas utilizó colores en la realización de sus historias. Quizás esto podría deberse a la influencia que ejerció en ellos la lectura de Emigrantes, libro que se construye en la gama de los sepias.

${ }^{6}$ En otra ocasión Carles señala que esta misma intencionalidad guía al ilustrador a realizar su obra sin utilizar gran diversidad de colores, pues "si fuese en color se vería más el sufrimiento y no quiere que se vea [...] quiere que se vea el sufrimiento pero no, no muy destacado".

${ }^{7}$ No sólo el color les permite reconocer las diversas historias insertas - como cajas chinas - en el texto primero, sino también la aparición del personaje principal de cada una. Cuando contemplamos juntos las breves pero potentes narraciones de la joven oriental, del hombre de gafas o del anciano que marchó a la guerra, los niños reconocen que se trata de otras historias diferentes del relato principal, pues en ellas no aparece en ningún momento el protagonista y sólo se muestra a cada uno de los personajes que, también emigrantes, le cuentan al protagonista sus experiencias. 